ISSN: 2542-0259

() Российское конкурентное право и экономика, 2018

\section{3.Х. Акбашева,}

ФАС России,

г. Москва

\section{О ключевых недостатках законодательства \\ о концессионных соглашениях}

\begin{abstract}
Аннотация
В статье дан критический анализ недостатков Федерального закона от 21 июля 2005 г. № 115-Ф3 «О концессионных соглашениях» в сравнении с сопоставимыми положениями Федерального закона от 05.04.2013 № 44-Ф3 «О контрактной системе в сфере закупок товаров, работ, услуг для обеспечения государственных и муниципальных нужд» с учетом практики заключения концессионных соглашений в Республике Башкортостан.

Вносится предложение о приведении законодательства о концессионных соглашениях в соответствие с общим законодательством о закупках.
\end{abstract}

Ключевые слова: концессионное соглашение, концедент, концессионер, закупки, внеконкурсные процедуры, ограничение конкуренции.

\title{
About key deficiencies legislation on concession agreements
}

\section{Z. Kh. Akbasheva,} FAS Russia, Moscow

\section{Annotation}

The article gives a critical analysis of the shortcomings of the Federal Law of July 21, 2005 No. 115-FZ "On concession agreements" in comparison with the comparable provisions of Federal Law No. 44-FZ of 05.04.2013 "On the contract system in the procurement of goods, works, services to ensure state and municipal needs ", taking into account the practice of concluding concession agreements in the Republic of Bashkortostan.

A proposal is made to bring the legislation on concession agreements in line with general procurement legislation.

Keywords: concession agreement, concessionaire, concessionaire, purchases, out-of-procedures, restriction of competition.

$\Pi$ роблемам совершенствования действующего законодательства России о концессионных соглашениях и практики его применения посвящено большое число научных работ [1-3]. Вместе с тем, несмотря на все усилия законодателя (на 1 января 2018 г. соответствующий федеральный закон с момента вступления его в силу был поправлен законодателем 22 раза), не удалось устранить, на наш взгляд, ключевые недостатки этого законодательства.

Федеральным законом от 21.07.2005 № 115-Ф3 «О концессионных соглашениях» (далее - Закон о концессионных соглашениях) предусмотрен порядок проведения конкурса на право заключения концессионного соглашения [4].

Однако на практике нередки случаи проведения конкурсных процедур в соответствии с порядком, предусмотренным Законом о концессионных соглашениях, по нашему мнению, в нарушение правил, установленных Федеральным законом 
от 05.04.2013 № 44-Ф3 «0 контрактной системе в сфере закупок товаров, работ, услуг для обеспечения государственных и муниципальных нужд» (далее - Закон о контрактной системе), регулируются отношения, направленные на обеспечение государственных и муниципальных нужд [5].

Порядок проведения конкурсных процедур, установленный Законом о контрактной системе, более открытый, прозрачный, обеспечивает, на наш взгляд, более высокий уровень эффективности, в большей степени способствует предотвращению коррупции и иных злоупотреблений, созданию прозрачной конкурентной среды и равных условий для всех участников, привлечению всех заинтересованных лиц.

Так, Законом о контрактной системе установлен определенный перечень требований, которым должны соответствовать участники закупки, тогда как Закон о концессионных соглашениях лишь ограничивается указанием на то, что конкурсная документация не должна содержать требования, необоснованно ограничивающие доступ какого-либо из участников конкурса к участию в конкурсе и (или) создающие кому-либо из участников конкурса преимущественные условия участия в конкурсе.

Критерии конкурса также устанавливаются решением о заключении концессионного соглашения, которые используются для оценки конкурсных предложений. Закон о концессионных соглашениях содержит только критерии конкурса в качестве возможных для установления.

При проведении конкурсных процедур в соответствии с Законом о контрактной системе установлено требование обосновать расчет начальной (максимальной) цены контракта, то есть изначально установить тот предел денежных средств, которые необходимы для исполнения контракта, что способствует рациональному и эффективному расходованию денежных средств.

В Законе же о концессионных соглашениях аналогичное требование отсутствует, кроме того, данный Закон не устанавливает требование о наличии в составе конкурсной документации итогового проекта концессионного соглашения, что не способствует созданию прозрачной конкурентной среды и свидетельствует о неравном подходе к потенциальным участникам конкурса.

Кроме того, Закон о концессионных соглашениях предусматривает заключение концессионного соглашения без проведения конкурса, в том числе по инициативе лиц, заинтересованных в заключении такого соглашения, и лицо, выступающее с инициативой заключения концессионного соглашения, вправе представить предложение о заключении концессионного соглашения с приложением проекта концессионного соглашения.

При этом какое-либо обоснование стоимости выполненных работ по концессионному соглашению не предусмотрено, то есть лицо, выступающее с инициативой заключения концессионного соглашения, вправе представить и сам проект концессионного соглашения, и предложение, что исключает возможность какоголибо контроля и проверки расчета стоимости работ, что, в свою очередь, приводит к перерасходованию бюджетных средств, тогда как те же самые работы могли бы быть выполнены более качественно и по наиболее низкой цене на основании результатов конкурсных процедур при выборе наилучшего исполнителя в соответствии с Законом о контрактной системе.

Данные факты подтверждаются многочисленными случаями снижения начальной (максимальной) цены контракта в ходе проведения конкурсных процедур. В некоторых случаях такое снижение достигает нескольких миллиардов рублей.

Например, по результатам проведения конкурса на право заключения контракта на строительство моста через реку Белая в г. Уфе начальная стоимость работ на объекте была снижена на треть: с 6,8 млрд руб. до 4,8 млрд руб. Несмотря на то, что проект строительства, на основе которого рассчитывалась минимальная цена, проходил государственную экспертизу, удалось получить экономию бюджетных средств на сумму в 2 млрд руб. При этом нужно учитывать, что полное финансирование строительства моста из бюджета отсутствовало и должно было применяться банковское кредитование контракта с последующим возмещением.

Таким образом, даже при установлении начальной цены контракта в соответствии с Законом о контрактной системе сохраняется вероятность снижения цены контракта на значительную сумму, поскольку цену предложения исполнитель формирует с учетом намерения получить прибыль по результатам исполнения контракта и с учетом себестоимости выполнения работ (оказания услуг). Фактическая же стоимость работ (как в указанном случае с мостом через реку Белая) может оказаться еще ниже.

Лишь проведение открытых конкурсных процедур в соответствии с Законом о контрактной системе способствует снижению начальной (максимальной) цены контракта и рациональному, эффективному расходованию бюджетных средств. При заключении же концессионного соглашения такая возможность отсутствует, тем более оно формируется по предложению участника и без проекта.

Возможность выбора из нескольких исполнителей наилучшего исполнителя или наиболее низкой цены при заключении концессионного соглашения, по нашему мнению, фактически отсутствует, в том числе по причине отсутствия обоснования и расчета объема необходимых инвестиций как такого.

Так, 12.05.2016 Государственным комитетом Республики Башкортостан по транспорту и дорожному хозяйству был объявлен конкурс 
№ 120516/13247324/02 на право заключения концессионного соглашения, объектом которого является совокупность участков автомобильной дороги общего пользования регионального значения Республики Башкортостан «Стерлитамак - Кага - Магнитогорск». Объем инвестиций из бюджета установлен в размере 8027991000 руб., и 2 млрд руб. должен был инвестировать концессионер.

При этом объект концессионного соглашения должен использоваться (эксплуатироваться) концессионером для организации проезда транспортных средств, в том числе платного проезда, со дня его ввода в эксплуатацию и до истечения срока действия концессионного соглашения.

Плата за проезд по платному участку автомобильной дороги в случае принятия соответствующего решения концедентом подлежит перечислению в бюджет Республики Башкортостан в соответствии с условиями концессионного соглашения, то есть итоговое решение о взимании платы за проезд принимается уже после заключения концессионного соглашения, порядок и условия взимания такой платы также определяются решением об использовании участка на платной основе и концессионным соглашением. Таким образом, отсутствует прозрачность условий в части получения прибыли в связи с организацией платного проезда.

Размер же концессионной платы, которая вносится концессионером единовременно за весь период эксплуатации, составляет 37116900 руб.

Концедент при этом принимает на себя часть расходов на создание объекта концессионного соглашения капитальный грант, размер, сроки и порядок выплаты которого определяются условиями концессионного соглашения, составленными в соответствии с конкурсным предложением концессионера и конкурсной документацией. Кроме того, в пользу концессионера после ввода объекта концессионного соглашения в эксплуатацию осуществляются платежи за эксплуатационную готовность объекта концессионного соглашения, размер, срок и порядок выплаты которых также определяются условиями концессионного соглашения.

Таким образом, как было указано выше, готовый проект соглашения, как и размер, сроки и порядок выплаты капитального гранта, платежей за эксплуатационную готовность объекта, отсутствуют и определяются уже после выбора концессионера, то есть на момент объявления конкурса на право заключения концессионного соглашения у потенциальных участников конкурса отсутствует в полной мере информация об условиях конкурса и концессионного соглашения, что препятствует созданию прозрачной конкурентной среды и создает возможность для злоупотреблений.

Так, 22.11.2016 на официальном сайте Единой информационной системы в сфере закупок [6] было размеще- но извещение о проведении электронного аукциона на право заключения государственного контракта на выполнение комплекса строительно-монтажных, пусконаладочных работ, включая оборудование, технологически и функционально связанное с процессом строительства по объекту «Строительство пристроя к существующему хирургическому корпусу ГБУЗ РКОД» с установлением условия банковского сопровождения контракта.

Начальная (максимальная) цена контракта была установлена в размере 1626433400 руб. согласно проекту, прошедшему госэкспертизу.

Для участия в указанной закупке поступили заявки от нескольких участников: ООО «Дортрансстрой» с ценовым предложением в размере 1610169066 руб. и 000 «Группа компаний СУ-10» с ценовым предложением 1618301233 руб. Таким образом, указанными участниками начальная (максимальная) цена контракта была снижена на 16264334 руб. и 8132167 руб. соответственно, то есть в случае заключения контракта по результатам проведенного аукциона экономия бюджетных средств составила бы значительную денежную сумму от 8 до 16 млн руб.

В связи с тем, что уполномоченным органом были неправомерно объединены в один объект закупки строительные работы и поставка товаров (оборудования), ФАС России было выдано предписание об аннулировании определения поставщика (подрядчика, исполнителя) на право заключения контракта, и 23.12.2016 указанная закупка была отменена.

Вместе с тем в настоящее время аналогичный объект «Реконструкция радиологического корпуса ГБУз “Республиканский клинический онкологический диспансер" Министерства здравоохранения Республики Башкортостан выставлен в качестве объекта концессионного соглашения ${ }^{1}$.

Правительственной комиссией Республики Башкортостан одобрено предложение частной инициативы ООО «ПЭТ-Технолоджи» по реализации проекта «Реконструкция радиологического корпуса ГБУз “Республиканский клинический онкологический диспансер”» Министерства здравоохранения Республики Башкортостан по заключению концессионного соглашения. Срок концессионного соглашения - 12 лет, общий объем инвестиций - 1 977,2 млрд руб., форма реализации проекта — концессия с эксплуатацией объекта соглашения.

При этом расчет, обосновывающий данный объем инвестиций в указанной выше сумме, отсутствует, как и отсутствует информация о величине затрат на работы, материалы, которые были учтены в данном объеме инвестиций.

В I квартале 2017 г. 000 «ПЭТ-Технолоджи» обратилось с соответствующей инициативой в Правительственную комиссию РБ. - Прим. авт. 
Кроме того, заключение концессионного соглашения вне проведения конкурсных процедур влечет, в свою очередь, закупку материалов, привлечение поставщиков, иные расходы исполнителя, связанные с исполнением обязательств по концессионному соглашению, также вне проведения закупочных процедур в отсутствие прозрачности, открытости, и, как результат - перерасходование бюджетных средств, расходы полностью возмещаются из фонда медицинского страхования.

В отношении тех или иных объектов имеется возможность применения неравного подхода: в отношении одного объекта проводится закупка в соответствии с Законом о контрактной системе, в то время как аналогичный объект передается как объект концессионного соглашения, то есть отсутствуют критерии, позволяющие разграничить применение Закона о контрактной системе и Закона о концессионных соглашениях.

Используя возможность заключения концессионного соглашения, уполномоченные органы и исполнители отстраняются от проведения закупочных процедур в соответствии с Законом о контрактной системе, что приводит к передаче всех крупных, дорогостоящих проектов по концессионному соглашению в обход Закона о контрактной системе, что, в свою очередь, приводит к неэффективному расходованию бюджетных средств.

При этом в соответствии с ч. 1 ст. 13 Закона о концессионных соглашениях концессионное соглашение заключается путем проведения конкурса на право заключения концессионного соглашения.

Заключение концессионного соглашения без проведения конкурса предусматривает соблюдение определенного порядка, который установлен ст. 37 Закона о концессионных соглашениях и который предусматривает размещение предложения о заключении концессионного соглашения на официальном сайте в сети Интернет с целью расширения круга потенциальных участников.

Предложение о заключении концессионного соглашения на официальном сайте единой информационной системы в сфере закупок в информационно-телекоммуникационной сети Интернет [7] в отношении объекта концессионного соглашения «Реконструкция радиологического корпуса ГБУз “Республиканский клинический онкологический диспансер” Министерства здравоохранения Республики Башкортостан не размещено. Однако даже в случае если соответствующий конкурс будет объявлен, участники рынка окажутся в неравных условиях, так как ООО «ПЭТ-Технолоджи» в течение года имело реальную возможность непосредственно изучать состояние объекта концессионного соглашения ГБУЗ «Республиканский клинический онкологический диспансер». После заседания соответствующей Правительственной комиссии, УФАС по Республике Башкортстан информировало органы прокуратуры в РБ.
Ненадлежащее извещение о заключении концессионного соглашения или о проведении конкурса является нарушением прав и законных интересов неопределенного круга лиц, влечет за собой сужение круга потенциальных участников и, как следствие, приводит к ограничению конкуренции.

Подобные действия могут содержать признаки нарушения ст. 16 Федерального закона от 26.07.2006 № 135-Ф3 «0 защите конкуренции» (запрет на ограничивающие конкуренцию соглашения или согласованные действия органов власти и хозяйствующих субъектов).

Выполненный анализ позволяет заключить, что законодательство о концессионных соглашениях нуждается в существенных изменениях, направленных на приведение его в соответствие с общим законодательством о закупках. Без решения этой проблемы цели привлечения эффективных инвестиций в различные секторы экономики, которые на сегодня не представляют очевидного интереса для частного инвестора, не будут достигнуты.

\section{Литература}

1. Вилисов М.В. Проблемы реализации закона о концессионных соглашениях // Недвижимость и инвестиции. Правовое регулирование. 2005. № 4.

2. Раднаев Б.В. Некоторые проблемы применения Закона о концессионных соглашениях // Вестник Санкт-Петербургского ун-та. Серия 14. Право. 2014. Вып. 1. С. 62-69.

3. Акбашева 3. Х., Максимова М. А. Государственночастное партнерство и публичные закупки: опыт, проблемы и пути совершенствования правого механизма // Российское конкурентное право и экономика. 2017. № 4. С. 34-43.

4. Собрание законодательства РФ. 25.07.2005. № 30 (ч. II). Ст. 3126.

5. Собрание законодательства РФ. 08.04.2013. № 14. СT. 1652

6. www.zakupki.gov.ru. Дата обращения: 22.11.2016.

7. www.torgi.gov.ru. Дата обращения: 12.03.2018.

\section{Сведения об авторе}

Акбашева Зульфира Хабибулловна: кандидат экономических наук, заслуженный экономист Республики Башкортостан, профессор Уфимского государственного нефтяного технического университета, помощник руководителя ФАС России

Контактная информация:

Адрес: 125993, г. Москва, ул. Садовая-Кудринская, д. 11 Тел.: +7 (499) 755-23-23 